\title{
A rare case of imatinib mesylate induced acute kidney injury
}

\author{
Ratna Agrawal*, Kaustav Saha, Sabita Mohapatra
}

Department of Pharmacology, V. S. S. Medical College, Burla, Sambalpur, Odisha, India

Received: 18 May 2016

Accepted: 13 June 2016

\section{*Correspondence to:}

Dr. Ratna Agrawal,

Email: ratna.arang@gmail.com

Copyright: (C) the author(s), publisher and licensee Medip Academy. This is an openaccess article distributed under the terms of the Creative Commons Attribution NonCommercial License, which permits unrestricted noncommercial use, distribution, and reproduction in any medium, provided the original work is properly cited.

\begin{abstract}
Imatinib is a revolutionary targeted molecule strikingly successful in chronic phase of chronic myeloid leukemia and higher doses are beneficial in the accelerated phase of the disease. It's known adverse effects include abdominal pain, vomiting, fluid retention, periorbital edema, pleural effusion, myalgia, liver damage and congestive heart failure. Renal damage due to this drug has not been well reported. In this case, the patient developed acute kidney injury as evidenced by raised creatinine level after two months of administration of imatinib mesylate. At $4^{\text {th }}$ visit, the levels of urea and creatinine were significantly above the upper normal limit. The patient was kept under supervision of his renal status and at the starting of $5^{\text {th }}$ visit decision was made to change the drug from imatinib to nilotinib. Currently the patient is tolerating nilotinib well. Causality assessment using WHO scale revealed imatinib to have possibly caused this rare adverse reaction.
\end{abstract}

Keywords: Chronic myeloid leukemia, Imatinib, Renal failure, Creatinine

\section{INTRODUCTION}

Imatinib mesylate, a specific inhibitor of a number of tyrosine kinase enzymes including BCR-ABL has revolutionized treatment of chronic myeloid leukemia (CML) and is now the first line therapy which allows most patients to have a good quality of life when compared to the former chemotherapeutic drugs.

It is generally well tolerated. Its adverse effects include abdominal pain, vomiting, fluid retention, periorbital edema, pleural effusion, myalgia, liver damage and congestive heart failure. ${ }^{1}$ Acute renal failure represents an infrequent side effect of imatinib, only few such cases have been reported till date. ${ }^{2}$

\section{CASE REPORT}

CLB, a 50 year old man presented to the Out Patient Department of Medicine of V. S. S Medical College, Burla, on $2^{\text {nd }}$ May 2015, with complaints of pain and distension of abdomen, swelling of both lower limbs, constipation and malaise. The patient was normotensive, non-diabetic and euthyroid. There was no past history of tuberculosis, respiratory disease, cardiac disease, dyslipidemia or renal impairment. His personal history revealed that he smoked (10 bidis/day) and occasionally chewed betel leaf. He was not on any medication at home.

His baseline investigations revealed $\mathrm{Hb}-7 \mathrm{gm} / \mathrm{dl}$, WBC1.8 lacs/cumm, DLC-N68 L5 B22 E2 M0, blast cells$18 \%$, myeloid: erythroid ratio-60:1, platelet count-2.4 lacs/cumm, serum creatinine- $0.9 \mathrm{mg} / \mathrm{dl}$. Abdominal examination revealed hepatomegaly with massive, tender splenomegaly extending to suprapubic region. Bone marrow examination revealed hypercellular marrow with suppressed erythropoiesis and markedly accelerated granulopoiesis with all stages of maturation of myeloid series seen. Fluorescent in situ hybridization (FISH) revealed Philadelphia chromosome (t 9;22). 
A diagnosis of chronic myeloid leukemia in accelerated phase was made and the patient was referred to Department of Radiotherapy, V. S. S. Medical College, Burla in May, 2015.
Patient was immediately started on imatinib mesylate 400 mg once daily orally. Whole blood transfusion was given and supportive therapy with esomeprazole $40 \mathrm{mg}$, cyanocobalamin $1000 \mathrm{mcg}$, multi vitamin, gabapentin $300 \mathrm{mg}$ all were given once daily.

Table 1: Records of hematological parameters (on imatinib therapy).

\begin{tabular}{|c|c|c|c|c|}
\hline Blood parameters & Visit 1 2/5/2015 & Visit 2 13/6/2015 & Visit 3 17/7/2015 & Visit 4 22/8/2015 \\
\hline $\mathrm{Hb}(\mathrm{gm} \%)$ & $7 *$ & $7 *$ & $8 *$ & $7 *$ \\
\hline WBC (/cumm) & $180000^{*}$ & $65000 *$ & $38000 *$ & 8600 \\
\hline Blast cells in peripheral smear & $18 \% *$ & $10 \% *$ & $8 \% *$ & $5 \% *$ \\
\hline Platelet count (/cumm) & 2.4 lakh & 2 lakh & 1.8 lakh & $1.5 \mathrm{lakh}$ \\
\hline RBS (mg \%) & 87 & 95 & 97 & 89 \\
\hline Urea (mg/dl) & 27 & 36 & 35 & $39 *$ \\
\hline Creatinine $(\mathrm{mg} / \mathrm{dl})$ & 0.9 & $1.24 *$ & $1.38 *$ & $2.4^{*}$ \\
\hline
\end{tabular}

$*=$ indicates abnormal levels.

Table 2: Records of hematological parameters (on nilotinib therapy).

\begin{tabular}{|c|c|c|c|c|}
\hline Blood Parameters & Visit 5 10/9/2015 & Visit 6 12/10/2015 & Visit 7 15/11/2015 & Visit 8 18/12/2015 \\
\hline $\mathrm{Hb}(\mathrm{gm} \%)$ & $7.4^{*}$ & $8 *$ & $8 *$ & $8.5^{*}$ \\
\hline WBC (/cumm) & 8000 & 7500 & 7200 & 7000 \\
\hline Blast cells in peripheral smear & $5 \% *$ & $4 \% *$ & $2 \% *$ & $2 \% *$ \\
\hline Platelet count (/cumm) & 1.4 lakh & 1.5 lakh & 1.8 lakh & 2 lakh \\
\hline RBS (mg \%) & 87 & 95 & 97 & 89 \\
\hline Urea (mg/dl) & $40 *$ & $36 *$ & $32 *$ & 20 \\
\hline Creatinine $(\mathrm{mg} / \mathrm{dl})$ & $2.4 *$ & $1.9 *$ & $1.2 *$ & 0.9 \\
\hline
\end{tabular}

$*=$ indicates significant reversal of abnormalities.

One month after starting of treatment, the edema subsided and the WBC count started reducing as revealed in Table 1. Patient was improving symptomatically and progression of CML from accelerated to blast crisis was halted. The patient was tolerating imatinib well, except that his creatinine level was raised $(2.4 \mathrm{mg} / \mathrm{dl})$ shown in Table 1 . He was advised to come for monthly check up for follow up investigations. His urea and creatinine levels continued to rise at $4^{\text {th }}$ visit $(39 \mathrm{mg} / \mathrm{dl}$ and 2.4 $\mathrm{mg} / \mathrm{dl})$. He was referred to Nephrologist who advised him tablet sodium bicarbonate $500 \mathrm{mg}$ once daily.

The patient was kept under supervision of his renal status and at the starting of $5^{\text {th }}$ visit decision was made to change the drug from imatinib to nilotinib $300 \mathrm{mg}$ twice a day. Slowly urea and creatinine levels started to return towards normal limits and by the end of 8th visit the levels came down to normal $(20 \mathrm{mg} / \mathrm{dl}$ and $0.9 \mathrm{mg} / \mathrm{dl})$ as shown in Table 2. But patient was still kept under supervision for his renal status because nilotinib also belongs to same group. Currently the patient is tolerating nilotinib well.

Informed consent was taken from the patient and records of his hematological parameters over a period of eight visits (from May, 2015 to December, 2015) are depicted in Table 1 and 2.

Causality assessment using WHO scale revealed imatinib to have possibly caused this rare adverse reaction.

\section{DISCUSSION}

Here is a case of chronic myeloid leukemia in accelerated phase showing significant improvement with tablet imatinib, but developing raised urea and creatinine levels indicating renal impairment, a rare event. Tong et al reported renal dysfunction during treatment with imatinib in $12 \%$ of patients with normal renal function at base line. ${ }^{2}$ Few case reports have indicated that acute tubular necrosis (ATN) is the cause and tubular vacuolization was observed in proximal and distal tubules. ${ }^{3}$

The molecular mechanisms by which imatinib induces ATN are not yet understood. Imatinib targets the platelet derived growth factor receptor (PDGFR) and c-kit expressed in kidney. Proximal tubule expression of PDGFR has been reported. ${ }^{4}$ In patients with ATN, proliferation and regeneration of proximal tubular cells depends upon PDGFR activation. ${ }^{4}$ Therefore, imatinib 
blockade of the PDGF pathway might promote ATN, especially in case of pre-existing renal failure.

Literature review revealed daily imatinib doses up to 600 or $800 \mathrm{mg}$ were well tolerated by patients with mild and moderate renal dysfunction, respectively, despite their having increased imatinib exposure. ${ }^{5}$ It may be prudent to reduce the initial dose of imatinib given to patients with severe renal dysfunction until more experience is gained in this subset of patients.

The renal injury was possibly caused by imatinib which reversed on substituting it with nilotinib. However it may be prudent to closely monitor patients on tyrosine kinase inhibitors for acute kidney injury.

\section{ACKNWOLEDGEMENTS}

Authors are thankful to Dr. Kabita Manjari Majhi (Associate Professor), Department of Radiotherapy, V. S. S. Medical College, Burla, Sambalpur, Odisha, India for her valuable opinion.

Funding: No funding sources Conflict of interest: None declared Ethical approval: Not required

\section{REFERENCES}

1. Chu E, Alan C. Cancer chemotherapy. In: Katzung BG, Trevor AJ, editor. Basic and clinical pharmacology. $13^{\text {th }}$ ed. New Delhi: McGraw-Hill; 2015:936-7.

2. Tong WG, Kantarjian H, O'Brien S, Faderl S, Ravandi F, Borthakur G, et al. Imatinib front-line therapy is safe and effective in patients with chronic myelogenous leukemia with pre-existing liver and/or renal dysfunction. Cancer. 2010;116:3152-9.

3. Francois H, Coppo P, Hayman JP, Fouqueray B, Mougenot B, Ronco P, et al. Partial fanconi syndrome induced by imatinib therapy: a novel cause of urinary phosphate. Am $\mathbf{J}$ Kidney Dis. 2008;51:298-301.

4. Kitiyakara C, Atichartakarn V. Renal failure associated with a specific inhibitor of BCR-ABL tyrosine kinase, STI571. Nephrol Dial Transplant. 2002;17(4):685-7.

5. Gibbons J, Egorin ML, Ramanathan RK, Fu P, Mulkerin DL, Shibata S, et al. Phase I and pharmacokinetic study of imatinib mesylate in patients with advanced malignancies and varying degrees of renal dysfunction: a study by the national cancer institute organ dysfunction working group. J Clin Oncol. 2008;26:570-6.

Cite this article as: Agrawal R, Saha K, Mohapatra S. A rare case of imatinib mesylate induced acute kidney injury. Int J Basic Clin Pharmacol 2016;5:1678-80. 